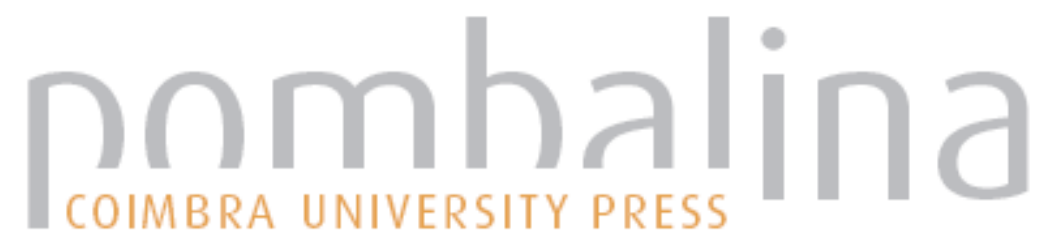

(8)

\section{A two-dimensional reaction-advection-diffusion model of the spread of fire in wildlands}

\author{
Autor(es): $\quad$ Grasso, Paolo; Innocente, Mauro S. \\ Publicado por: Imprensa da Universidade de Coimbra \\ URL \\ persistente: URI:http://hdl.handle.net/10316.2/44553 \\ DOI: $\quad$ DOI:https://doi.org/10.14195/978-989-26-16-506_36 \\ Accessed : $\quad$ 26-Apr-2023 11:34:57
}

A navegação consulta e descarregamento dos títulos inseridos nas Bibliotecas Digitais UC Digitalis, UC Pombalina e UC Impactum, pressupõem a aceitação plena e sem reservas dos Termos e Condições de Uso destas Bibliotecas Digitais, disponíveis em https://digitalis.uc.pt/pt-pt/termos.

Conforme exposto nos referidos Termos e Condições de Uso, o descarregamento de títulos de acesso restrito requer uma licença válida de autorização devendo o utilizador aceder ao(s) documento(s) a partir de um endereço de IP da instituição detentora da supramencionada licença.

Ao utilizador é apenas permitido o descarregamento para uso pessoal, pelo que o emprego do(s) título(s) descarregado(s) para outro fim, designadamente comercial, carece de autorização do respetivo autor ou editor da obra.

Na medida em que todas as obras da UC Digitalis se encontram protegidas pelo Código do Direito de Autor e Direitos Conexos e demais legislação aplicável, toda a cópia, parcial ou total, deste documento, nos casos em que é legalmente admitida, deverá conter ou fazer-se acompanhar por este aviso.

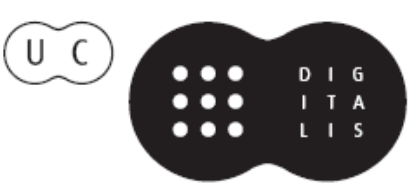




\section{ADVANCES IN}

\section{FOREST FIRE RESEARCH}

\section{8}

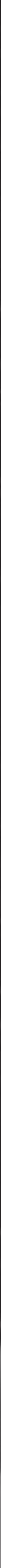




\title{
A two-dimensional reaction-advection-diffusion model of the spread of fire in wildlands
}

\author{
Paolo Grasso; Mauro S. Innocente \\ Smart Vehicles Control Laboratory (SVeCLab), Coventry University. UK. \\ \{grassop@uni.coventry.ac.uk, Mauro.S.Innocente@coventry.ac.uk\}
}

\begin{abstract}
The aim of this research is to develop a model of the spread of wildfires that is computationally efficient and easy-to-use, yet comprehensive enough to capture the major phenomena that govern the behaviour of a real fire. Namely, the pyrolysation of wood; the combustion of a mono-phase medium composed of premixed gas of fuel and air; the heat transferred by diffusion, convection and radiation considering emission and absorption of hot semi-transparent gases; and the thermal energy transport due to atmospheric wind and spatial distribution of vegetation. The model consists of two coupled partial differential equations, one representing the mass formation of each chemical species involved in the combustion, and the other ensuring the balance of enthalpy. The dimensionality reduction sought by modelling these three-dimensional (3D) phenomena in two-dimensional (2D) space is an intricate problem that has been overcome by means of pseudo-3D terms in the energy balance equation. For instance, the convection in the direction perpendicular to the 2D domain of the model has been represented as heat loss whose magnitude is linearly dependent on the temperature difference between the ambient and the simulation domain. Thus, the pseudo-3D convection term acts as a sink of thermal energy. It is important to note, however, that some environment properties have necessarily been disregarded in the interest of efficiency. Thus, the effect of topography on the spread of fire has been ignored in this model. In addition, the balance of momentum in the simulation plane is not included in the formulation as air density is considered independent of temperature and the wind velocity field is steady-state and uniform. Furthermore, the diffusion coefficient is augmented to account for the energy transport due to convection inside the flattened vegetal substrate, which is abstractly represented as a premixed gaseous layer. This augmentation has been calibrated for particular environment conditions such as the porosity of the fuel and its spatial distribution so that the model can be used as a tool for prediction of fire propagation. Making use of the $4^{\text {th }}$-Order Runge-Kutta method and running simulations for different constraints and boundary-initial conditions, results appear realistic. The presented fire-spread model is aimed at supporting the design of innovative fire management and suppression technologies and strategies, as well as to function as a decision-support tool to assist fire fighters in the use of current technology. Hence it must be both realistic and computationally efficient. Nonetheless, a more advanced 3D high-fidelity model is currently under development at the other end of the spectrum of the accuracy/efficiency trade-off with the aim to provide better insight into the fire dynamics.
\end{abstract}

Keywords: wildfire propagation, modelling, reaction, advection, diffusion, fuel, combustion, radiation, suppression.

\section{Introduction}

Modelling wild fires is a real challenge because of its complex combination of several interdependent phenomena acting at different length scales. Few researchers have attempted to handle this cumbersome problem. According to the methodologies utilised, the different fire models can be grouped in classes. Based on the mathematical formulation adopted, models can be classified as either continuous or cellular automata based (Sullivan, 2009, p.349; Sullivan, 2009, p.369; Papadopoulos and Pavlidou, 2010; Séro-Guillaume et al., 2008). The first group consists of models based on the laws of physics, with mathematical formulations in terms of coupled partial differential equations typically including balances of mass, momentum and energy. Instead, the cellular automata approach models the domain as a set of nodes that can have only a discrete number of states - e.g. unburnt, burning or 
burnt. In (Anez et al., 2017), a multilayer cellular automaton was used to model smouldering using three layers: the fuel (ash, char, dry fuel, wet fuel), the heat layer (heat release, no heat, heat losses), and oxygen (oxygen or nitrogen). This allowed a far more detailed estimation of the fire dynamics compared with the simpler burnt/burning/unburnt scheme. The evolution in time of the automata is determined by probabilistic transition laws that involve the state of the neighbouring nodes. The advantage of the cellular automata approach over the physics-based one is its considerably faster computation.

One of the most eminent continuous models of wildfire that can be found in the literature was developed by members of the Laboratoire d'Energetique et de Mechanique Theorique et Appliquee (LEMTA) (Séro-Guillaume and Margerit, 2002; Margerit and Séro-Guillaume, 2002). It is a threedimensional (3D) multiphase and multiscale wildfire model which elegantly depicts the fire phenomena from the smallest to the largest scale. In fact, they believe the repertoire of fire models should be classified according to the length-scale to be investigated: microscopic scale, where vaporisation and pyrolysis of the solid fuel are the main involved phenomena; mesoscopic scale, at which the geometry of the vegetation (leaves, branches, etc.) heavily affects the heat fluxes from solid to surrounding air; macroscopic scale, where the combustion occurs; and gigascopic scale, where the fire is driven by atmospheric wind and topography. A way to overcome this complexity and modelling at large scales in order to have a faster simulation is upscaling through averaging and by the convenient use of Large Eddy Simulation (LES) for turbulence modelling. But one of the most severe limitations of large-scale models are the errors associated with point-to-point comparison, which is critical given than the rate of spread is very sensitive to small variations (Houssami et al., 2018).

Furthermore, the available freeware simulators of wildfire can also be differentiated between continuous and cellular automata based models. The most well known simulators world-wide are FARSITE (Finney, 1998), Prometheus (Tymstra et al., 2010) and the Fire Dynamics Simulator (FDS) (McGrattan and Forney, 2004; McGrattan, 2006). The first two are based on the same Huygens principle for the determination of the fire front perimeter, which consists of the envelope contour of ellipses whose focuses are located in the previous step's fire-front, and whose shapes depend on many environmental parameters (e.g. wind) and fuel properties (e.g. moisture level). These fire simulators are mostly focused on determining the fire spread efficiently in order to assist fire management operations. On the other hand, FDS is more focused on capturing as many detailed features of fire phenomena as possible. It can be both 2D and 3D and makes use of the direct physics approach. SéroGuillaume et al. (Séro-Guillaume et al., 2008) acknowledge two main types of continuous approaches to modelling fire. The one adopted by Margerit et al. (Margerit and Séro-Guillaume, 2002) simplifies and averages from the most complex and detailed mathematical formulation to the most practical one that can be more easily implemented numerically. Conversely, the FDS approach starts from the simplest 3D gaseous-phase combustion model and adds complexity through the development of several submodels that are superposed to the main simulation and interact with it - e.g. volume-less Lagrangian particles (McGrattan, 2006) used to model solid firebrand particles floating in the air and exchanging mass, momentum and energy with the fluid while reacting with it. These submodels usually have mostly empirical bases, steming from extensive and expensive experimental observations. Some recent submodels either developed or under development are as follows:

- Correlation between the firebrand generation and the fire behaviour in order to determine fluxes, sizes and separation distances (Thomas et al., 2017, p. 864-871).

- Development of smouldering models (combustion of solid microporous media), both numerical (Anez et al., 2017) and empirical ones.

- Wildland-urban interface Fire Dynamics Simulator (WFDS), which is and extension of the American National Institute of Standards and Technology's (NIST) FDS. 
- Regarding upscaling techniques: determining the heat transfer coefficient between solid and fluid phases at macroscopic level using a surrogate model based on numerical experiments of the heat transfer throughout a fractal model of vegetation geometry (Collin and Lamorlette, 2012).

- Radiation, which is a very complex problem, especially if the whole spectrum is considered.

- Incomplete combustion models (mostly empirical) due to variation of oxygen flux (Thomas et al., 2017, p.855-863).

There is extensive debate upon which fire modelling approach is the best in capturing its dynamics. For instance, Papadopoulos (Papadopoulos and Pavlidou, 2010) states that FARISTE "is considered to be the most precise fire propagation simulation model by most of the researchers around the world", whilst Sullivan (Sullivan, 2009) claims that still FARSITE and Prometheus are the best simulators found in literature that can reproduce historical fires. At the same time, there are other research centres that focus their attention on the direct physics approach, proudly acclaiming its rigour in detecting the fire dynamics. For example, FDS is the result of 25 years of collaboration between many researchers across the world, whilst LEMTA's fire-spread models have been developed during 15 years of work. In line with (Séro-Guillaume et al., 2008), we are interested in classifying fire models according to their purpose, for instance to achieve a fast (possibly real-time) prediction or to capture some microscale phenomena.

The aim of this research is to model the spread of forest fire efficiently in order to support the design of innovative fire management and suppression technologies and strategies, while also comprising a decision-support tool to assist fire-fighters in their use of current technology. Therefore, the model must be at the same time efficient and comprehensive enough to capture the major phenomena that govern the behaviour of a real fire.

The proposed fire-spread model is given by a $2 \mathrm{D}$ reaction-advection-diffusion equation that describes the combustion of a mono-phase medium composed of premixed gas of fuel and air. It can be placed in the 2D direct-physics semi-empirical reaction-diffusion class of fire spread models, and it is similar to the Ferragut's (Ferragut et al., 2007) and Margerit's (Margerit and Séro-Guillaume, 2002) 2D models. By reducing dimensionality, some phenomena of fire dynamics are disregarded, e.g. the buoyancy due to density changes of the medium immersed in a gravitational field. The energy transport due to atmospheric wind is modelled, though the wind field is limited at this stage to be steady-state and uniform throughout the 2D space considered. The effect of the slope and that of the water vapour pressure are left to be accounted for in a 3D model that is currently being developed. Another simplifying assumption is that $2 \mathrm{D}$ convection is negligible, which is reasonable since the velocities induced by density variation in the horizontal plane are very small, with the resulting energy transport comprising less than $1 \%$ of the total energy fluxes. Considering that buoyancy is not modelled and assuming that the chemical reaction rate depends mostly on temperature and mole fractions of fuel and oxygen, the density variation due to temperature changes has no strong effect on the fire dynamics modelled. Hence density is assumed to be constant, and the momentum balance and mass conservation are not formulated. Thus, the mixed gases are confined within their original location, just as if pyrolysis gasses were to be burnt exactly where they had been released. The diffusion coefficient is corrected in this efficient model in order to account for the energy transport due to $2 \mathrm{D}$ convection inside the premixed layer - i.e. in the vegetation stratum. Furthermore, two pseudo-3D terms are added into the energy balance equation with the intention of modelling the energy losses due to convection and radiation in the direction perpendicular to the $2 \mathrm{D}$ domain being modelled (vertical direction). Horizontal radiation is modelled so as to affect only the neighbouring cells, since the cell size in the discretised domain can be set larger than the optical thickness or radiation absorption length. The heat capacity at constant pressure of each chemical species is considered to be constant 
and equal to an average value in the considered temperature range, from $T_{\mathrm{amb}}=293 \mathrm{~K}$ (ambient temperature) to approximately $1200 \mathrm{~K}$ (maximum temperature). Although, in the eventuality of strong wind, the temperature may rise to peaks of $1500 \mathrm{~K}$.

\section{The 2D Wildfire Spread Model}

The considered irreversible chemical reaction in (2.1) represents the combustion of the pyrolysis gasses in air, which is composed of oxygen, carbon dioxide, vapour and nitrogen.

$$
\mathrm{CH}_{4}+2 \mathrm{O}_{2} \rightarrow \mathrm{CO}_{2}+2 \mathrm{H}_{2} \mathrm{O}
$$

The fire-spread model can be represented by a system of five coupled partial differential equations, namely the enthalpy balance in (2.2) and the four equations in (2.3) for the consumption or formation of each chemical species (Fuel, $\left.\mathrm{O}_{2}, \mathrm{CO}_{2}, \mathrm{H}_{2} \mathrm{O}\right)$, i.e. $\mathrm{j}=1, \ldots, 4$.

$$
\begin{aligned}
\frac{\partial T}{\partial t} & =F_{T}\left(T, X_{j}\right) \\
\frac{\partial X_{j}}{\partial t} & =F_{X_{j}}\left(T, X_{j}\right)
\end{aligned}
$$

Equation (2.2) is expanded in (2.4) where the phenomenon modelled by each term is clearly labelled, namely: 1) the combustion energy term including the combustion enthalpy $\left(h_{c}\right)$ and the reaction rate; 2) the transport term accounting for atmospheric wind; 3) the diffusion terms; 4) the pseudo-3D convection term accounting for energy loss by vertical convection; the $2 D$ radiation terms; and the pseudo-3D radiation term modelling vertical emission.

$$
\begin{gathered}
\rho c_{p} \frac{\partial T}{\partial t}=\overbrace{-\rho h_{c} \frac{M}{M_{1}} r}^{\text {Combustion }} \overbrace{-\rho c_{p} u_{i}^{*} \frac{\partial T}{\partial x_{i}}}^{\text {Diffusion }}+\ldots \\
\overbrace{k \frac{\partial}{\partial x_{i}}\left(\frac{1}{c_{p}} \frac{\partial c_{p} T}{\partial x_{i}}\right)+k \frac{\partial}{\partial x_{i}}\left(\frac{1}{c_{p}} \frac{\partial h_{c} T}{\partial x_{i}}\right)}^{\text {Transport }}+\ldots \\
\overbrace{\sigma \varepsilon\left[4 d x_{i} \frac{\partial}{\partial x_{i}}\left(T^{3} \frac{\partial T}{\partial x_{i}}\right)\right]}^{\overbrace{C_{a}\left(T_{\text {amb }}-T\right)}}+\ldots \overbrace{\sigma \varepsilon\left[\frac{T_{\text {amb }}^{4}-T^{4}}{d x_{3}}\right]}^{\text {pseudo3D-Radiation }} \\
\frac{\partial X_{i}}{\partial t}=-\frac{\theta_{i}}{\theta_{\text {fuel }}} \frac{M}{M_{\text {fuel }} r} ;
\end{gathered}
$$

In order to close the system composed by (2.4) and (2.5), additional closure equations are required, in particular for:

- The molar mass of the mixture $(M)$ in (2.6), which is the weighted summation of each chemical species molar mass $\left(M_{i}\right)$ by their mass fractions $\left(X_{i}\right)$.

- The constant pressure heat capacity of the mixture $\left(c_{\mathrm{p}}\right)$ in (2.7), which is the weighted summation of all the partial heat capacities $\left(c_{\mathrm{p} i}\right)$.

- The combustion rate $(r)$ following the Arrhenius law in (2.8), where the subscripts ' 1 ' stands for fuel and ' 2 ' for oxygen. The formulation is the empirical formula related to wood pyrolysis 
in (Ragland et al., 1991). Bear in mind the pre-exponential coefficient $\left(A_{\mathrm{r}}\right)$ for following discussion.

- The specific combustion enthalpy $\left(h_{\mathrm{c}}\right)$ in (2.9), which is the summation of all the formation enthalpies at the local temperature $(T)$.

$$
\begin{gathered}
M=\sum_{i=1}^{5} X_{i} M_{i} \\
c_{p}=\sum_{i=1}^{5} X_{i} \frac{M_{i}}{M} c_{p i} \\
r\left(T, X_{1}, X_{2}\right)=-\delta_{\left(T, X_{1,2}\right)}^{+} A_{r} T X_{1}^{0.5} X_{2} \exp \left(-\frac{T_{\mathrm{a}}}{T}\right) \\
h_{c}=\frac{H_{c}(T)}{M}=-\frac{1}{M} \sum_{i=1}^{5} \theta_{i} H_{i}(T)=\frac{1}{M} \sum_{i=1}^{5} \theta_{i}\left(H_{i, \mathrm{ref}}+M_{i} c_{p i}\left(T_{\mathrm{ref}}-T\right)\right)
\end{gathered}
$$

The conductivity $(k)$, the pre-exponential coefficient $\left(A_{r}\right)$ and the optical absorption length $\left(\mathrm{d} x_{i}\right)$ have been calibrated (see Table 2) using the results obtained by FARSITE simulator (Finney, 1998), not having any experimental data available at the moment. The representative values considered are the burnt area, radius, and the maximum temperature. Given that the burning (a.k.a. flaming) area can be smaller than the burnt area, the latter has been chosen for calibration purposes as the flaming area is very dynamic and its estimation affected by the numerical model used.

For instance, we performed two exemplar calibrations for two types of fuels structurally different: the values in Table 2 have been obtained for the fuel model FM3 (tall coarse grass) and FM10 (coniferous trees) (Scott and Burgan, 2005). More precisely, FM10 consists of $15 \mathrm{~m}$ trees with $4 \mathrm{~m}$ base, whose canopy coverage has been set to $100 \%$ in the presented simulations, with a density of $0.2 \mathrm{~kg} \cdot \mathrm{m}^{-}$ 3 . Moreover, the selected elevation is $300 \mathrm{~m}$ and the moisture level about $20 \%$. The remaining known parameters and some characteristic variables are listed in Table 1.

Please note that the optical absorption length, for radiation modelling, has to be smaller than or equal to the cell size in order for the model to be valid. Moreover, the asymptotic wind magnitude, above the vegetation stratum, has to be reduced in order to take the drag into account. Hence the modified wind velocity $\left(u_{i}^{*}\right)$ in $(2.4)$ is obtained by multiplying the wind velocity by a reduction coefficient $(w r)$, which is a function of the fuel type and of the canopy coverage. The higher the canopy coverage and the denser the fuel type, the smaller the reduction coefficient. For instance, by our calculations during calibration phase, $10 \mathrm{~m} / \mathrm{s}$ for FM10 corresponds to approximately $1.3 \times 10^{-3} \mathrm{~m} / \mathrm{s}$ in the premixed gas layer.

\section{Results and Discussion}

The simulations have been performed on a $100 \mathrm{~m} \times 100 \mathrm{~m}$ domain, and their results appear realistic from both qualitative and quantitative point of views. However, in order to use this simulation tool for prediction of fire propagation, the parameters of the model must be calibrated for particular environmental conditions, including fuel properties and spatial distribution. 
Table 1 - General settings for simulation of fire spread with fuel model FM10. (* calibrated parameters)

\begin{tabular}{l|l|r|l} 
Symbol & Description & Value & Units \\
\hline$R$ & Universal gas constant & 8.314 & $\mathrm{~J} \cdot \mathrm{mol}^{-1} \cdot \mathrm{K}^{-1}$ \\
\hline$T_{\mathrm{amb}}\left(T_{\mathrm{ref}}\right)$ & Ambient (reference) temperature & 298.15 & $\mathrm{~K}$ \\
\hline$T_{\mathrm{ig}}$ & Ignition temperature & 573 & $\mathrm{~K}$ \\
\hline$T_{\mathrm{a}}$ & Activation temperature & 684 & $\mathrm{~K}$ \\
\hline$P_{\mathrm{amb}}\left(P_{\text {ref }}\right)$ & Ambient (reference) pressure & 101325 & $\mathrm{~Pa}$ \\
\hline$\rho$ & Gas mixture density & 1.2172 & $\mathrm{~kg} \cdot \mathrm{m}^{-3}$ \\
\hline$A_{\mathrm{r}}$ & Pre-exponential coefficient (Arrhenius) & $(*)$ & - \\
\hline$C_{\mathrm{a}}$ & Turbulent convection coefficient in atmosphere & 0.065 & $\mathrm{~J} \cdot \mathrm{m}^{-3} \cdot \mathrm{K}^{-1} \cdot \mathrm{s}^{-1}$ \\
\hline$k$ & Thermal conductivity & $(*)$ & $\mathrm{W} \cdot \mathrm{m}^{-1} \cdot \mathrm{K}^{-1}$ \\
\hline$c_{\mathrm{p}}$ & Specific heat capacity at constant pressure & calculated & $\mathrm{J} \cdot \mathrm{kg}^{-1} \cdot \mathrm{K}^{-1}$ \\
\hline$X_{\mathrm{f}}$ & Initial fuel molar fraction & 0.1 & - \\
\hline$\sigma$ & Stefan-Boltzmann constant & $5.6704 \mathrm{e}-8$ & $\mathrm{~W} \cdot \mathrm{m}^{-2} \cdot \mathrm{K}^{-4}$ \\
\hline$\varepsilon$ & Emissivity factory (<1) & 0.55 & - \\
\hline $\mathrm{d} x_{i}$ & Optical absorption length & $(*)$ & $\mathrm{M}$ \\
\hline $\mathrm{d} x_{3}$ & Optical absorption length in z direction & 1 & $\mathrm{M}$ \\
\hline$h_{c}$ & Specific combustion enthalpy & calculated & $\mathrm{J} \cdot \mathrm{kg}^{-1}$ \\
\hline$w r$ & Wind reduction coefficient & $(*)$ & - \\
\hline$\Delta t$ & Time step & 7.5 & $\mathrm{~S}$ \\
\hline$\Delta x=\Delta y$ & Cell-size & 1 & $\mathrm{M}$
\end{tabular}

Table 2 - Values of parameters describing the fuel model FM3 and FM10.

\begin{tabular}{c|c|c|c} 
Symbol & $F M 3$ & $F M 10$ & Units \\
\hline$k$ & $5.5703 \mathrm{e}-01$ & $6.3750 \mathrm{e}-02$ & $\mathrm{~W} \cdot \mathrm{m}^{-1} \cdot \mathrm{K}^{-1}$ \\
\hline$A_{\mathrm{r}}$ & $4.1699 \mathrm{e}-05$ & $6.6250 \mathrm{e}-06$ & - \\
\hline $\mathrm{d} x_{i}$ & 0.4 & 0.1 & $\mathrm{~m}$ \\
\hline$w r$ & $7.5106 \mathrm{e}-5$ & $1.3075 \mathrm{e}-04$ & -
\end{tabular}

Figure 1.a shows the classical ring-shaped flame front, which has been used for calibration purposes, spreading radially from the ignition points at the same rate for uniformly distributed fuel and no wind. In case of both single and multiple ignition points and zero wind condition, the estimation error of the burnt area (with respect to FARSITE simulation) is less than $1 \%$.

In turn, Figure 1.b shows the energising effect of wind: the flame front is distorted, the area affected by the fire is enlarged, and the maximum temperature increases (from $1215 \mathrm{~K}$ to about $1297 \mathrm{~K}$ in this case). The presence of wind results in a 'teardrop' shape of the fuel consumption due to the asymmetric spread of the fire, as can be observed in Figure 2.b. In presence of wind and with single/multiple ignition points, the estimation error of the burnt area oscillates between less than $1 \%$ to approximately $30 \%$ (for very intense wind of up to $80 \mathrm{~m} / \mathrm{s}$ speed). The stronger the wind, the larger the discrepancies between FARSITE simulations and the presented model simulations. It is hard to assess whether one or the other are the most correct simulator of reality, but for sure a large part of the error is inherent to the mathematical formulation and the numerical methods that have been used, let alone the dimensionality reduction. It is interesting to note that in those regions where flames persist in the same location, for instance at zero wind condition or in particular stagnation points, the fuel mass fraction 
tends to zero (Figure 2.a) whereas the fuel tends to be only partially consumed in the presence of wind (Figure 2.b) as the flame is blown away from the original ignition points.
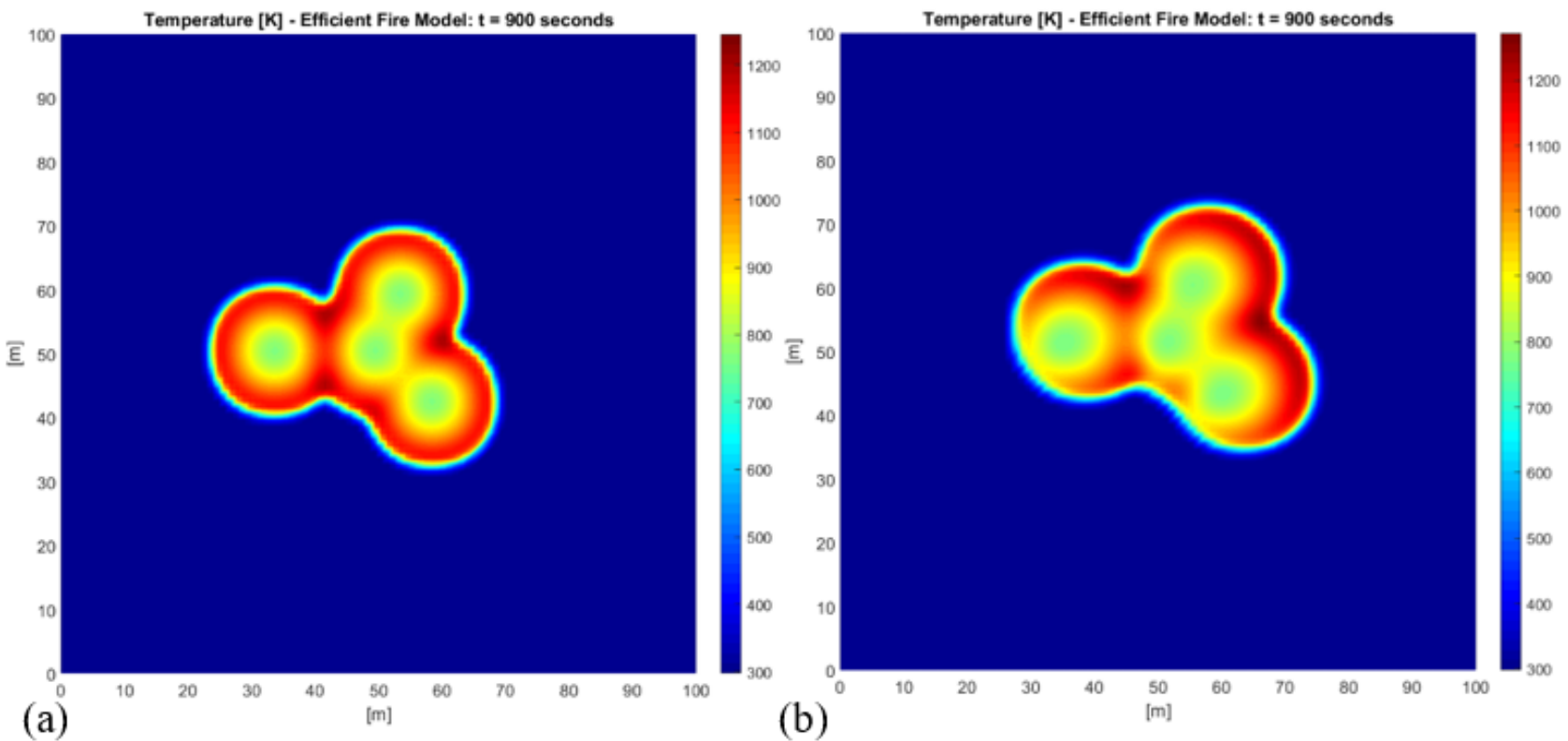

Figure 2 - Flaming Area: Temperature field at 15 min after four-points random ignition (a) without wind and (b) with strong wind of $40 \mathrm{~m} / \mathrm{s}$ for FM10.
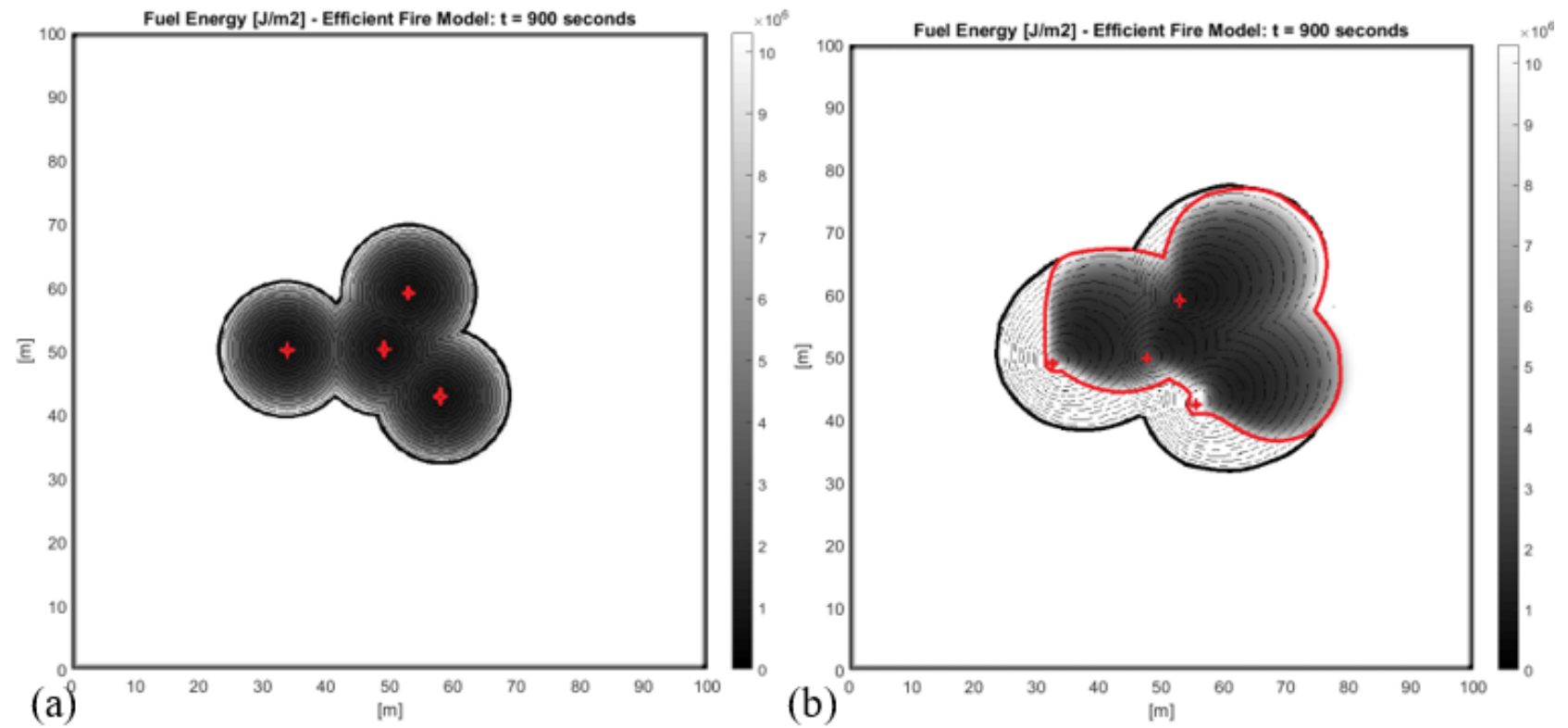

Figure 3 - Burnt Area: Distribution of fuel energy at 15 min after four-points random ignition (a) without wind and (b) with strong wind of $40 \mathrm{~m} / \mathrm{s}$ for FM10. The red stars represent the ignition points (the same of Figure 1), and black areas correspond to zero-fuel condition. The thick black contour corresponds to FARSITE prediction, while the red one is obtained by the presented model.

\section{Conclusion}

The output of the presented research is a successful attempt to simulate efficiently and with a high level of accuracy the spread of wildfires with the use of a macroscopic two-dimensional reaction- 
advection-diffusion model. The developed model shows its versatility to be calibrated for any type of fuel models, tackling any environmental condition (except for topography) - e.g. moisture and wind. Thanks to its simplicity and computational lightweight (e.g. on a standard quad-core i7 computer, it predicts $1 \mathrm{~min}$ of fire dynamics in approximately $1 \mathrm{sec}$ computational time for $10^{4}$ unit cells), this model has been coupled with a swarm of drones (Innocente and Grasso, 2018) in order to develop an autonomous technology to either extinguish or mitigate wildfires. The use of this robust technology aims to considerably lower the risks to human lives during firefighting operations. Thus, the presented model is both realistic and computationally efficient. Nonetheless, a more advanced and intensive 3D high-fidelity model is currently under development with the aim to provide more accurate insight into the fire dynamics.

\section{References}

Anez NF, Christensen K and Rein G (2017) Two-dimensional model of smouldering combustion using multi-layer cellular automaton: The role of ignition location and direction of airflow. IAFFS $12^{\text {th }}$ Symposium. Fire Safety Journal.

Collin A and Lamorlette A (2012) Quantification of convective heat transfer inside tree structures. Journal of Physiscs: Conference Series, IOP Publishing, 395, 012145

Ferragut L, Asensio M and Monedero S (2007) A numerical method for solving convection-reactiondiffusion multivalued equations in fire spread modelling. Advances in Engineering Software, vol. 38, no. 6, pp. 366-371

Finney MA (1998) FARSITE: Fire Area Simulator-Model development and evaluation. USDA Forest Service, Rocky Mountain Research Station Research Paper RMRS-RP-4. (Ogden, UT)

Houssami ME, Lamorlette A, Morvan D, Hadden RM and Simeoni A (2018) Framework for submodel improvement in wildfire modeling. Combustion and Flame, Elsevier BV, 190, 12-24

Innocente MS, Grasso P (2018) Swarms of autonomous drones self-organised to fight the spread of wildfires. Proceedings of the RSFF'18 Workshop, L'Aquila, Italy

Margerit J and Séro-Guillaume O (2002) Modelling forest fires. Part II: reduction to two-dimensional models and simulation of propagation. International Journal of Heat and Mass Transfer, vol. 45, no. 8, pp. 1723-1737, 2002.

McGrattan KB and Forney GP (2004) Fire dynamics simulator User's Guide (version 4). VTT \& NIST, National Institute of Standards and Technology

McGrattan KB (2006) Fire dynamics simulator Technical Reference Guide Volume 1: Mathematical Model (version 4). VTT \& NIST, National Institute of Standards and Technology

Papadopoulos GD and Pavlidou FN (2010) A Comparative Review on Wildfire Simulators. International Scientific Journal

Ragland KW, Aerts DJ and Baker AJ (1991) Properties of Wood for Combustion Analysis. Bioresource Technology

Sullivan AL (2009) Wildland surface fire spread modelling, 1990-2007. 1: Physical and quasiphysical models. International Journal of Wildland Fire, CSIRO Publishing, 18 , 349

Sullivan AL (2009) Wildland surface fire spread modelling, 1990-2007. 2: Empirical and quasiempirical models. International Journal of Wildland Fire, CSIRO Publishing, 18 , 369

Scott JH and Burgan RE (2005) Standard Fire Behavior Fuel Models: A Comprehensive Set for Use with Rothermel's Surface Fire Spread Model. USDA Forest Service, Rocky Mountain Research Station Research Paper RMRS-GTR-153. (Ogden, UT) 
Séro-Guillaume O and Margerit J (2002) Modelling forest fires. Part I: a complete set of equations derived by extended irreversible thermodynamics. International Journal of Heat and Mass Transfer, vol. 45, no. 8, pp. 1705-1722

Séro-Guillaume O, Ramezani S, Margerit J and Calogine D (2008) On large scale forest fires propagation models. International Journal of Thermal Sciences

Thomas JC, Mueller EV, Santamaria S, Gallagher M, Houssami ME, Filkov A, Clark K, Skowronski N, Hadden RM, Mell W and Simeoni A (2017) Investigation of firebrand generation from an experimental fire: Development of a reliable data collection methodology. Fire Safety Journal, Elsevier BV, 91 , 864-871

Thomas JC, Hadden RM and Simeoni A (2017) Experimental investigation of the impact of oxygen flux on the burning dynamics of forest fuel beds. Fire Safety Journal, Elsevier BV, 2017 , 91 , 855863

Tymstra C, Bryce RW, Wotton BM, Taylor SW and Armitage OB (2010) Development and Structure of Prometheus: the Canadian Wildland Fire Growth Simulation Model - Information Report NORX-417. Northern Forestry Centre \& Canadian Forest Service, Northern Forestry Centre \& Canadian Forest Service 